Rudy W. Herlambang, Diana Lukitasari, IGN Tri Marutama, Galih Pranata

EKSOTISME ARSITEKTUR BANGUNAN BELANDA DAN ARSITEKTUR BANGUNAN JAWA TERHADAP PENERAPAN TEKNIK TIMELAPSE VIDEO (TINJAUAN BANGUNAN CAGAR BUDAYA KOTA SURAKARTA)

\title{
EKSOTISME ARSITEKTUR BANGUNAN BELANDA DAN ARSITEKTUR BANGUNAN JAWA TERHADAP PENERAPAN TEKNIK TIMELAPSE VIDEO (TINJAUAN BANGUNAN CAGAR BUDAYA KOTA SURAKARTA)
}

\author{
Rudy W. Herlambang ${ }^{1}$, Diana Lukitasari ${ }^{2}$, IGN Tri Marutama ${ }^{3}$, Galih Pranata ${ }^{4}$ \\ (DKV)-FSRD Universitas Sebelas Maret Surakarta ${ }^{1,3}$, Fakultas Hukum Universitas Sebelas Maret \\ Surakarta $^{2}$ \\ Pascasarjana Universitas Sebelas Maret Surakarta ${ }^{4}$ \\ Email: rudywicaksono@staff.uns.ac.id
}

\begin{abstract}
This study examines the form of attraction between the Dutch heritage heritage building and Javanese buildings in Surakarta City. The aim of the research is to explore the exoticism that is presented through two different building forms, namely the Dutch building and the Javanese building. The results of the study show that the branding strategy through video timelapse provides its own attraction as a media of renewal in the world of the promotion of the digital era. In Surakarta, Dutch buildings such as Benteng Vastenburg, save the elegant and robust side of the building, while in the architecture of Javanese buildings in the Keraton Surakarta building there is an element of philosophy as a symbol of the center of Javanese civilization in Surakarta.
\end{abstract}

Key Words: Architectural Ecosystem, Dutch Buildings, Javanese Buildings, Timelapse, Surakarta

\begin{abstract}
Abstrak: Penelitian ini mengkaji mengenai bentuk daya tarik antara bangunan cagar budaya peninggalan Belanda dengan bangunan Jawa di Kota Surakarta. Tujuan penelitian ini adalah mengeksplorasi eksotisme yang dihadirkan melalui dua bentuk bangunan yang berbeda, yakni bangunan Belanda dan bangunan Jawa. Hasil dari penelitian menunjukkan bahwa strategi branding melalui video timelapse memberikan daya tarik tersendiri sebagai media kebaharuan dalam dunia promosi era digital. Pada bangunan Belanda Surakarta seperti halnya Benteng Vastenburg, menyimpan sisi elegan dan kekokohan pada bangunan, sedangkan pada arsitektur bangunan Jawa pada bangunan Keraton Surakarta terdapat unsur falsafah sebagai simbol pusat peradaban Jawa di Surakarta.
\end{abstract}

Kata kunci: Ekosistem Arsitektur, Bangunan Belanda, Bangunan Jawa, Timelapse, Surakarta

Upaya pelestarian bangunan dan/atau lingkungan cagar budaya di Indonesia menjadi isu penting dan berkembang sekitar tahun 1990 dalam penataan ruang di Indonesia. Pelestarian adalah upaya dinamis untuk mempertahankan keberadaan Cagar Budaya dan nilainya dengan cara melindungi, mengembangkan, dan memanfaatkannya. Adanya peraturan dan keputusan yang dikeluarkan oleh pemerintah demi mempertahankan keaslian bangunan dan/ atau lingkungan cagar budaya ini rupanya tidak mengurangi potensi pengrusakan ataupun pemugaran bangunan cagar budaya dan perubahan fungsi lahan pada kawasan cagar budaya. Pada kenyataanya saat ini, bangunan cagar mulai kehilangan daya tariknya karena telah berubah wajah akibat perilaku masyarakat yang apatis hingga melakukan pengrusakan terhadap tubuh bangunan cagar (Wirastari \& Suprihardjo, 2012). Sejarah Indonesia yang kental dengan nilai-nilai tradisional dan menjunjung tinggi budaya leluhur dapat menarik wisatawan untuk mengunjungi tempat-tempat bersejarah untuk mencari tahu atau mempelajari sejarah dan budaya bangsa Indonesia pada zaman kuno (Permana, et al., 2015).

Pelestarian cagar budaya juga dapat dilakukan melalui penghayatan terhadap 
bangunan cagar, termasuk diantaranya estetika arsitektur bangunan cagar. Arsitektur tradisional merupakan unsur kebudayaan nasional yang mempunyai struktur, fungsi, style, bentuk fisik atau proses pembuatannya senantiasa memberikan karakteristik tersendiri (Zain, 2012). Seperti halnya Kuil

Vodoun di Afrika yang mengalami transformasi pasca kerusakan, dibangun kembali serupa dengan material sederhana agar menjaga bentuk otentisitas dan estetika arsitekturnya (Vecco, 2010). Gaya arsitektur pertama mulai diperkenalkan melalui gambar atau sketsa dengan tangan yang bertujuan untuk menunjukkan proporsi di antara bagianbagian berbeda dari objek, sehingga memiliki estetika dan cenderung ekstotis (Andrés \& Pozuelo, 2009). Perkembangan arsitektur Eropa yang populer, tentunya memberikan pengaruh besar pada bentuk seni arsitektur Indonesia karena adanya pengaruh kolonialisme Belanda (Murwadani, 2007). Begitu juga langgam arsitektur Jawa yang idealis menjadi daya tarik bagi sejumlah wisatawan dengan konsep langgam jawa yang tradisional nan klasik (Wardhani \& Kusumawidagdo, 2019).

Arsitektur yang merupakan bentuk estetika dari seni tradisional menjadi paradigma yang masih eksis dan ekstotis (Herrington, 2007). Kehadiran bangunan cagar dengan seni arsitektur yang menarik dapat mendorong daya tarik wisatawan terhadap pertumbuhan pariwisata kota. Pengembangan potensi pariwisata dapat meningkatkan potensi ekonomi, sebagai konservasi dan perlindungan situs cagar (Nicholas, et al., 2009). Pelestarian cagar budaya dapat dilakukan melalui strategi branding mutakhir yang dikemas menarik dan relevan dengan jiwa zamannya. Saat ini, pembentukan citra cagar budaya penting, sehingga revitalisasi cagar budaya dapat menggunakan strategi branding untuk memperkenalkan potensi wisata melalui city branding (Jannah, et al, 2014). Strategi branding dapat dilakukan melalui pembuatan video yang berisi hal-hal yang menarik dan ikonik. Video branding dibuat dengan tujuan memperkenalkan potensi pariwisata kepada publik sealigus dapat menarik minat pengunjung (Fong, et.al, 2017). Penelitian ini mengkaji mengenai eksotisme arsitektur Keraton Kasunanan Hadiningrat sebagai simbolik langgam arsitektural Jawa dan Benteng Vastenburg dan bangunan Belanda di sekitarnya yang potensial menjadi citra budaya Kota Surakarta melalui penerapan strategi branding yang tepat.

\section{HASIL Sejarah dan Arsitektur Fort Vastenburg}

Awalnya, ketika benteng ini belum berukuran terlalu besar, namanya adalah De Grootmoedigheid yang memiliki arti 'sombong'. Gubernur Jenderal Baron van Imhoff mendirikan benteng ini pada tahun 1745. Benteng ini berdiri di antara Keraton Kasunanan Surakarta dengan Kantor Gubernur Belanda, yang sekarang adalah Balai Kota Surakarta. Sekitaran tahun 1750, pasukan Belanda menggunakan benteng ini untuk mengawasi Keraton Kasunanan Surakarta, mulai pemerintahan Paku Buwono III. Bahkan, dulunya di benteng ini sempat ada meriam yang diarahkan ke Keraton. Kemudian, di tahun 1775 hingga tahun 1779, dibuatlah benteng yang lebih besar, yang diberi nama Vastenburg atau 'istana yang dikelilingi tembok kuat.' Di dalam benteng terdapat kompleks bangunan yang pada masa itu merupakan rumah untuk prajurit beserta keluarganya. Selain itu, ada pula bangunan asrama yang mengelilingi benteng di beberapa titik. Tercatat bahwa benteng ini mengalami dua kali renovasi semasa pemerintahan Belanda dan Inggris. Renovasi yang pertama yaitu tahun 1794 saat VOC akan dibubarkan dan renovasi kedua adalah pada tahun 1832 ketika Belanda berhasil merebut kembali Indonesia dari penjajahan Inggris.

Di awal tahun 1990, benteng ini sempat ditutup dan pada tahun 1991, benteng ini sempat dijual ke perseorangan. Beberapa tahun sesudahnya, terjadi konflik kepemilikan hingga pada tahun 1992, Benteng Vastenburg diberi status sebagai Benda Cagar Budaya dengan UU No. 5 Tahun 1992. Semenjak itu, bangunan benteng masih tetap kurang diperhatikan hingga mengalami kerusakan di beberapa bagian hingga memberikan kesan horor. Namun, pada tahun 2014, restorasi mulai dilakukan, membuat bangunan benteng menjadi layak kembali, salah satunya dengan mengecat putih tembok benteng yang tadinya sudah berlumut dan pudar warnanya.

Meskipun begitu, masih diperlukan 
Rudy W. Herlambang, Diana Lukitasari, IGN Tri Marutama, Galih Pranata

EKSOTISME ARSITEKTUR BANGUNAN BELANDA DAN ARSITEKTUR BANGUNAN JAWA TERHADAP PENERAPAN TEKNIK TIMELAPSE VIDEO (TINJAUAN BANGUNAN CAGAR BUDAYA KOTA SURAKARTA)

perhatian khusus supaya benteng ini layak untuk dikunjungi sebagai tempat wisata sejarah.

Pada masa penjajahan kolonial Belanda di Indonesia, tetjadi perkembangan dari berbagai segi kehidupan, politik, sosial, budaya ekonomi, termasuk arsitektural. Arsitektur kolonial di Indonesia adalah fenomena yang unik, tidak terdapat di lain tempat. Hal ini tetjadi karena adanya percampuran budaya antara budaya penjajah kolonial Belanda dengan budaya Indonesia yang beraneka ragam, sehingga membuat bangunan kolonial Belanda di Indonesia mempunyai ciri tersendiri. Arsitektur Kolonial di Indonesia merupakan fenomena budaya yang unik, karena terjadi percampuran budaya antara pendatang dengan kebudayaan Indonesia yang beraneka ragam (Sumalyo, 1993). Arsitektur Eropa pada bangunan Belanda seperti terlihat pada Benteng Vastenburg tersebut, didirikan pada tahun 1832 yang berdasarkan desain arsitek VOC, A.H.B. von Neidschutz (Hernowo, 2015). Benteng Vastenburg memiliki luas 40.000 meter persegi dan berlokasi di Gladak, Surakarta. Bangunan tembok benteng ini secara umum sama dengan bentuk benteng di tempat-tempat lain. Bentuknya bujur sangkar dengan dinding batu bata setinggi 6 meter, serta penonjolan ruangan di setiap sudutnya. Di tengahnya terdapat lapangan yang cukup luas, dahulu berfungsi sebagai tempat dilaksanakannya upacara bendera atau persiapan pasukan. Mengelilingi tembok benteng yang tebal, terdapat parit yang digunakan sebagai perlindungan. Kini, parit tersebut sudah menjadi sempit dan dangkal, tidak selebar dan sedalam dulu. Dahulu juga terdapat jembatan angkat menuju ke pintu gerbang benteng di sisi barat dan timur.

Benteng kolonial Belanda memiliki fungsi tertentu menurut kebijakan dari penguasa-penguasa yang berkuasa pada masa itu. Benteng pada umumnya berbentuk segiempat dan mengelilingi wilayah kerajaan. Benteng kolonial ditunjang dengan bangunan lain seperti bangunan pengintai, parit, tanggul keliling, jembatan angkat dan bastilon yang kini menjadi bagian dari eksotisme bangunan bersejarah (Chawari, 2016). Perkembangan tipomorfologis bangunan Belanda di

Surakarta, tidak hanya berasal dari pengaruh negeri Belanda saja yang diserap, melainkan melalui negara-negara relevan di sekitarnya di Eropa berdasarkan era ragam arsitektur yang sedang berlaku, serta terdapat pula pengaruh karakter pribadi arsitek yang terlibat ataupun berpengaruh dalam perkembangan langgam arsitektural Belanda. Konsep arsitektur bangunan Belanda di Surakarta sebagai bentuk hasil serapan pengaruh dari negara-negara di sekitarnya atau dari luar Belanda (Renaisans). Pada era Renaisans di Eropa, khususnya Belanda sampai dengan Rasionalisme Awal yang terserap ke Belanda, yang sebenarnya terkait dengan orientasi; antara lain terkait dengan ruang terbuka kota (square), ataupun sumbu jalan.

Table 1. Fungsi arsitektur Belanda Benteng Vastenburg

\begin{tabular}{lll}
\hline Object & Philosophical Meaning & Figure \\
\hline $\begin{array}{l}\text { Morfologi } \\
\text { Vastenburg }\end{array}$ & $\begin{array}{l}\text { Benteng Vastenburg memiliki bentuk } \\
\text { morfologi menyerupai kura-kura } \\
\text { sebagai simbol pertahanan dir }\end{array}$ \\
& &
\end{tabular}


Pintu Gerbang

Parit

Dinding Benteng

Konidisi di dalam benteng Vastenburg

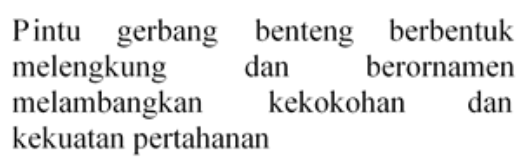
melengkung dan berornamen melambangkan kekokohan dan kekuatan pertahanan

Parit mengelilingi tubuh benteng sebagai bentuk pertahanan sekaligus pantangan bagi serangan musuh agar tidak masuk dengan mudah mendekati dinding benteng.

Benteng Vastenburg memiliki memiliki dinding yang tinggi sebagai upaya perlindungan dari intaian musuh.
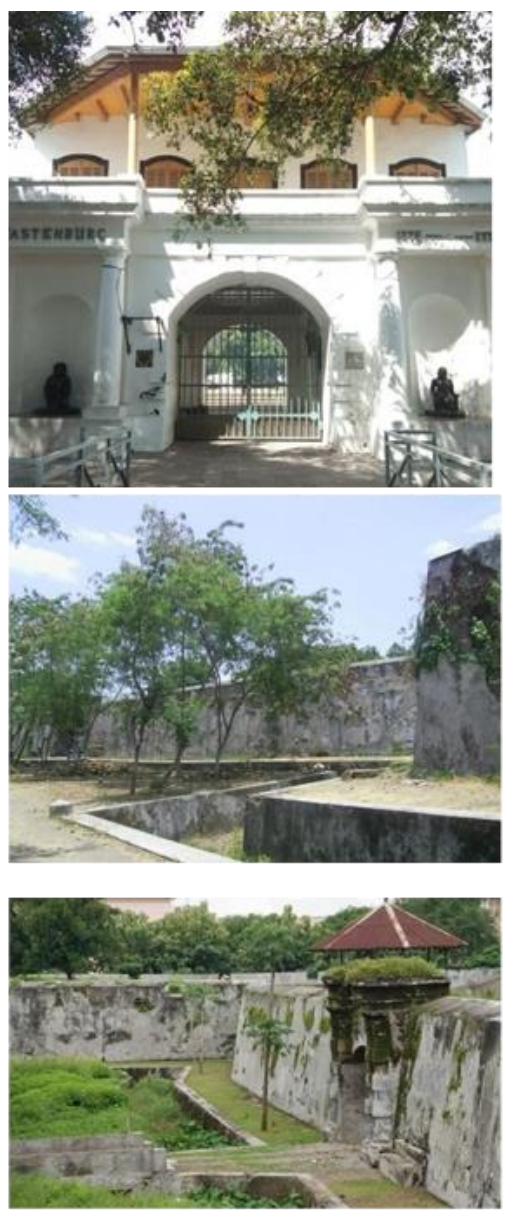

kondisi di dalam benteng yang megah, diperkirakan dulu merupakan kamp dan asrama prajurit Belanda.

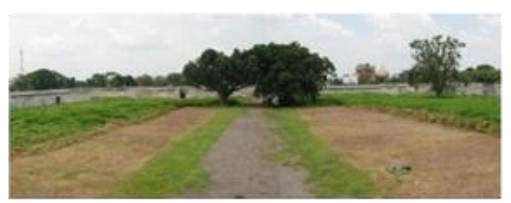

Secara umum, tata letak arsitektural Belanda cenderung menghadap jalan raya penting dengan di belakangnya terdapat kanal ataupun tidak. Begitupula dengan konsep bangunan Benteng Vastenburg yang berdiri kokoh menghadap ke sumbu jalan dan dikelilingi parit serta berdekatan dengan kanal. Semenjak adanya Grootmoedigheid, maka mulai berdirilah bangunan-bangunan kolonial lain di sekitarnya, (De Javasche Bank, Gedung DHC 1945, asrama militer

Belanda, Gereja St. Antonius, Societeit, Balaikota dan Pasar Gede) (Siregar, et al., 2017). Bangunan Belanda membentang di tepian jalan Surakarta mulai dari kawasan Gladak hingga menuju Keraton Surakarta, terlihat begitu eksotis. Lokasi bangunanbangunan Belanda dibuat dekat dengan Kraton sekaligus sebagai bentuk penghormatan terhadap Keraton Surakarta Hadiningrat. Agar tidak menyaingi keluasan dimensi serta tinggi menara Panggung Sanggabuwana, maka dibuatlah bangunanbangunan elit Belanda yang tingginya tidak melebihi tinggi menara Keraton (Lestari, 2016).

\section{Langgam Arsitektur Bangunan Jawa} Pada Keraton Kasunanan Surakarta Hadiningrat

Pola bangunan Jawa

tentunya memiliki karakteristik

tersendiri dalam perkembangannya. Hal tersebut dapat dilihat melalui langgam arsitektur rumah tradisional Jawa yang dikelompokkan sesuai status sosial pemiliknya mulai dari ningrat hingga rakyat biasa. Bentuk rumahnya berjenjang tingkatannya mulai dari 


\section{Rudy W. Herlambang, Diana Lukitasari, IGN Tri Marutama, Galih Pranata EKSOTISME ARSITEKTUR BANGUNAN BELANDA DAN ARSITEKTUR BANGUNAN JAWA TERHADAP PENERAPAN TEKNIK TIMELAPSE VIDEO (TINJAUAN BANGUNAN CAGAR BUDAYA KOTA SURAKARTA)}

joglo hingga kampung. Kategori ini berpengaruh pada pola tata ruang dan tata elemen arsitektural yang menyampaikan peran dan simbol tertentu. Dalam hal ini, lingkup fungsi bangunannya adalah rumah tinggal. Tata elemen arsitektural dibagi menjadi elemen pengisi, elemen pembatas, dan elemen pelengkap ruang (Markus et al, 1972). Tipologi arsitektur Jawa diklasifikasi terutama dalam karakter atap dan pembagian ruang. Bentuk bangunan terbagi dalam susunan mulai dari tingkatan yang tertinggi yaitu tajug (masjid), joglo (golongan ningrat), limasan (golongan menengah), kampung (rakyat biasa), dan panggang pe (rakyat biasa). Rumah-rumah tersebut memiliki jenis atap yang berbeda untuk menunjukkan kedudukan sosial dan ekonomi pemilik rumah (Cahyandari, 2012).

yang memimpin pemerintahan keraton, yakni dari masa pemerintahan Paku Buwana II hingga Paku Buwana XII. Perkembangan yang terjadi ternyata masih mengacu pada suatu konsep tata ruang keraton terdahulu yang terus dipertahankan dari masa ke masa (Hardiyanti, et al, 2005). Gaya arsitektur dan tata letak keraton didasari oleh prinsip yang berakar pada kosmologi Hindu-Jawa. Gunung Mahameru yang keramat pada pusat alam semesta dilambangkan dengan pendopo (balai pertemuan) dan taman dalem. Rangkaian Bangunan dan halaman yang terpencar dari pusat melambangkan daratan dan lautan. Berbagai bangunan dipisahkan oleh dinding yang tinggi dan pintu gerbang simbolis yang bukan saja menjadi lambang perbedaan tingkat

Table 2. Falsafah arsitektur Jawa pada bangunan Keraton

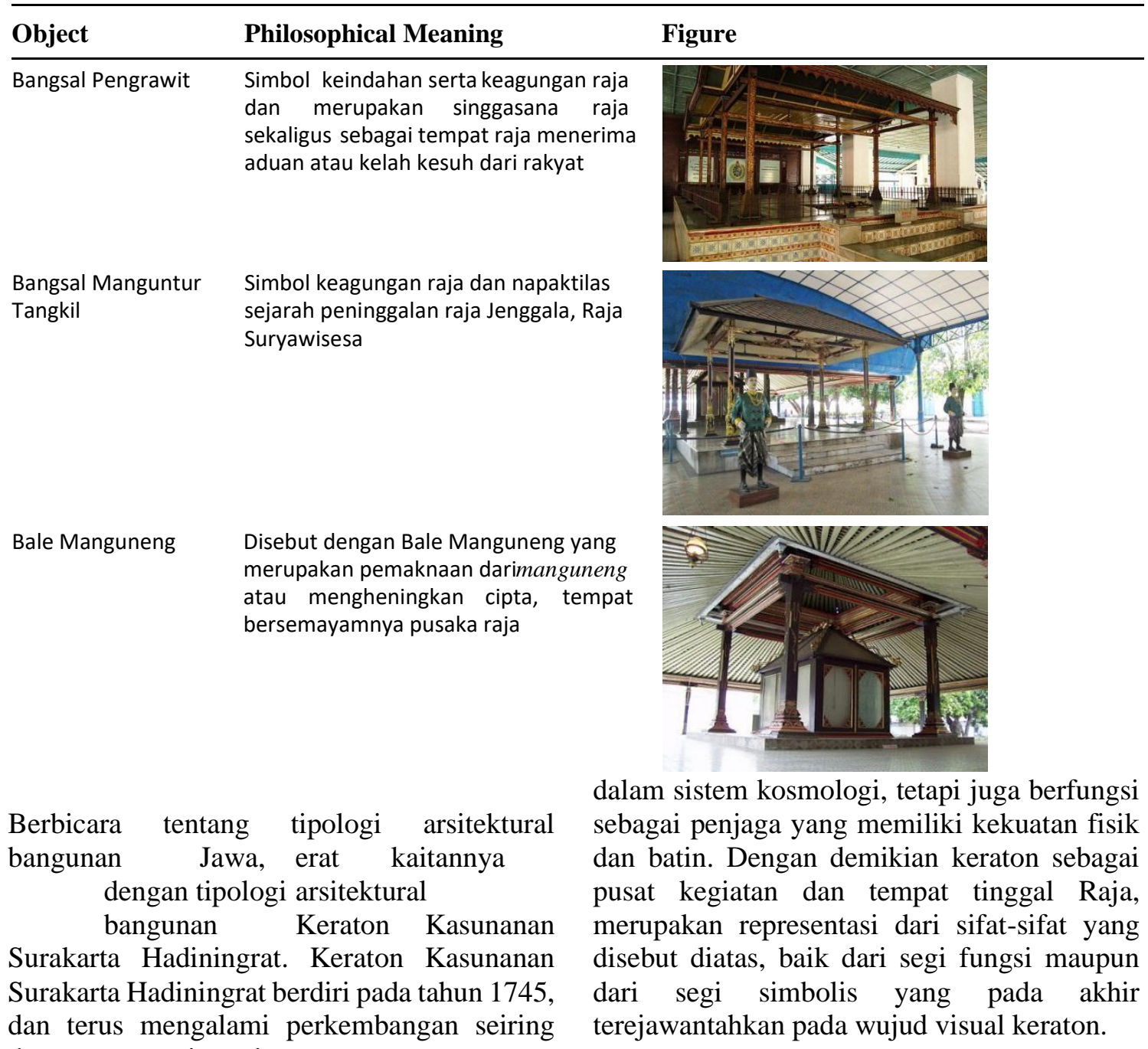

dengan pergantian raja 
Kori Brajanala Lor

Lampu interior Keraton Surakarta
Pintu masuk tempat berjaganya para pengawal Kesultanan Keraton Surakarta.

Salah satu unsur kebudayaan Jawa yang tetap lestari di komplek bangunan Keraton. Simbol kehidupan budaya Jawa Kuno

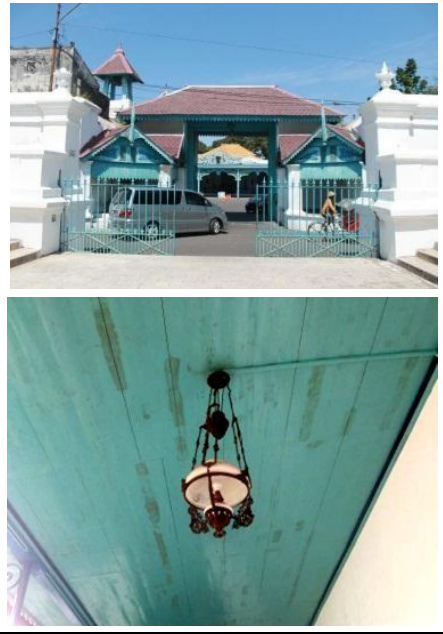

Terdapat motivasi yang muncul dari para wisatawan yakni karena rasa ingin tahu terhadap budaya Jawa yang eksotis dan motivasi fisiologis, yang dimana wisatawan akan berkunjung di waktu senggangnya. Dalam riset tersebut, belum dimunculkan strategi untuk menarik daya tarik wisatawan terhadap Keraton Surakarta yang secara potensial menjadi daerah wisata yang mengedukasi. Beberapa kendala di temukan sehingga sampai saat ini Keraton Surakarta masih minim pemgunjung. Terbatasnya sarana branding menjadi hal penting yang perlu diperhatikan dalam meningkatkan minat pengunjung. Perlunya menggunakan strategi branding yang menarik yang bisa dinikmati oleh masyarakat secara luas sehingga dapat meningkatkan potensi wisata terhadap pelestarian bangunan cagar budaya. Salah satu strategi branding yang dapat mengeksplorasi eksotisme dari bangunan cagar budaya adalah video branding dengan teknik timelapse.

Timelapse fotografi adalah teknik sinematografi dimana frekuensi waktu pengambilan gambar jauh lebih lama dari hasil videonya. Objek - objek dan waktu yang diambil dalam waktu beberapa menit ataupun bulan dapat dilihat hanya dengan waktu beberapa menit ataupun detik (Chylinski, 2012). Teknik timelapse merupakan sebuah animasi video, yaitu beberapa foto yang diurutkan hingga terlihat bergerak seperti halnya rekaman video. Timelapse adalah gabungan antara teknik fotografi dengan teknik editing video. Dengan mengunakan teknik ini, foto yang indah bisa kita nikmati dalam sebuah video. Yaitu dengan cara mangambil beberapa foto yang berurutan dalam beberapa waktu, 
Rudy W. Herlambang, Diana Lukitasari, IGN Tri Marutama, Galih Pranata

EKSOTISME ARSITEKTUR BANGUNAN BELANDA DAN ARSITEKTUR BANGUNAN JAWA TERHADAP PENERAPAN TEKNIK TIMELAPSE VIDEO (TINJAUAN BANGUNAN CAGAR BUDAYA KOTA SURAKARTA)

kemudian menggabungkan dan mengurutkan foto-foto tersebut menjadi sebuah video (Herdian et al., 2015). Teknik Timelapse sangat mirip halnya dengan animasi Stop Motion, tapi ada perbedaan sedikit dengan Stop Motion, jika Stop Motion penggabungan foto 3 tidak harus memperlihatkan perbedaan waktu yang lama, karena teknik Stop Motion hanya membuat benda seolah-olah bergerak. Sedangkan teknik Timelapse, pengambilan foto harus lama agar terlihat pergerakan sesuatu yang lambat dari waktu ke waktu, seperti contoh dari siang ke malam, bunga seminggu yang mekar, pergerakan bintang dan lain-lain.

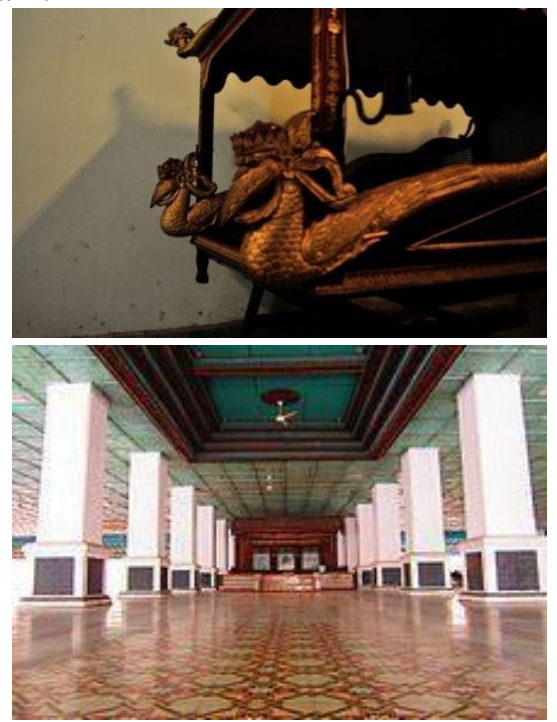

Gambar 1. Eksotisme desain intrior dan tata ruang Keraton Kasunanan Surakarta Kereta Kencana Kyai Garuda dan Siti Hinggil Surakarta

Tujuan dari timelapse photography pada awalnya adalah untuk kebutuhan penelitian, dimana gerakan yang sangat lambat direkam dan ditampilkan dalam laju yang dipercepat untuk diamati gerakannya (hal yang berkebalikan dengan slow motion video). Untuk gerakan yang amat sangat lambat bahkan timelapse bisa dibuat periodik dalam hitungan menit (bukan detik), misal untuk mempelajari pertumbuhan tanaman / bunga, peneliti memotret setiap 15 menit selama berhari-hari (Herdian et al., 2015). Video branding dengan teknik timelapse dapat membuat video dengan durasi yang panjang di ubah kedalam durasi yang lebih singkat tetapi tidak mengubah isi di dalamnya. Penggunaan teknik timelapse dalam video ini juga di dukung dengan narasi yang dibacakan oleh narator untuk memperjelas keterangan gambar. Selain itu juga di dukung dengan pemilihan lagu sebagai latar belakang untuk membuat video ini menjadi lebih menarik.

Pada tahap pembuatan video dengan teknik time lapse, terdapat berbagai persiapan. Dalam hal ini, saat menggunakan teknik time lapse perlu mengatur kamera di mode Aperture Priority untuk mengatasi pencahayaan. Atur di ISO tinggi untuk suasana redup atau ISO rendah untuk suasana cerah. Mengatur white balance. Mengatur Intervalometer agar dapat menghasilkan ratusan foto dalam satu jam. Menekan Auto Exposure Lock agar kamera bisa mengatur pencahayaan secara otomatis. Menekan Shutter dan gunakan aplikasi penunjang dalam pembuatan video, seperti halnya Adobe After Effect. Dalam tahap persiapan ini, perlu juga menyesuaikan tone dari masing-masing bangunan sebagai objek yang akan ditangkap fenomenanya. Pada bangunan Belanda, termasuk diantaranya benteng Vastenburg Surakarta yang merupakan bangunan outdoor akan mengedepankan visualisasi gambar terbaik di ruangan terbuka. Sedangkan apabila dalam mengambil gambar mengenai bangunan Jawa yang mengedepankan estetika interiornya, diperlukan kematangan perspektif terhadap bangunan interior atau perkiraan kualitas cahaya di dalam ruangan.

Video dengan menggunakan teknik timelapse dapat menawarkan nilai - nilai estetis yang mendorong viewers ke dalam suasana atau suatu objek. Chylinski (2012) menegaskan bahwa video dengan teknik timelapse mengedepankan visualisasi objek objek dan waktu yang diambil dalam waktu beberapa menit ataupun bulan dapat dilihat hanya dengan waktu beberapa menit ataupun detik. Video timelapse merupakan perwujudan dari perekaman progresif suatu objek. Dalam hal ini, pola pergerakan dan perubahan menjadi syarat mutlak tercapainya keindahan dalam video berteknik timelapse.

Keindahan bangunan benteng Vastenburg dan beberapa bangunan Belanda di sekitarnya lebih cenderung menekankan pada perubahan dan pergerakan awan dan angin sebagai medium terciptanya citra positif terhadap objek bangunan Belanda. Desain interior dan makna filosofis di setiap ornamen 
yang terdapat di dalam bangunan Jawa, seperti halnya Keraton Kasunanan Surakarta dapat dibuat melalui pergeseran dan pergerakan kamera dalam mengelilingi scope objek yang terdapat dalam bangunan Keraton.

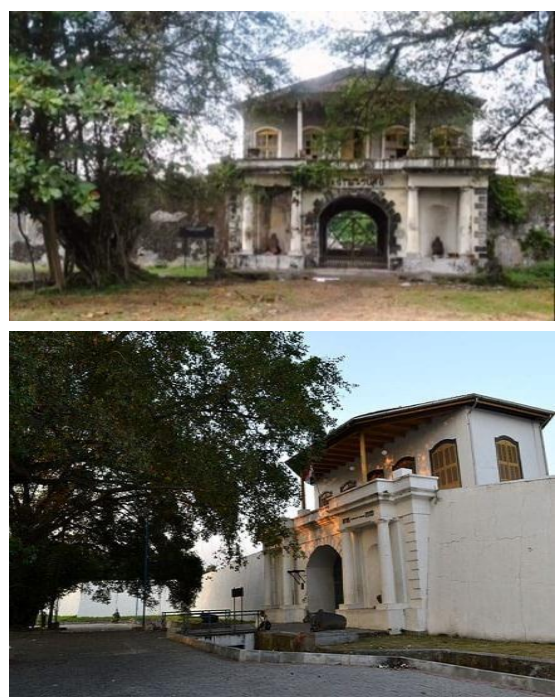

Gambar 2. Eksotisme ruang terbuka pada dinding luar dan panorama alam sekitar Fort Vastenburg, Surakarta

Video timelapse menggambarkan secara progresif objek yang terekam dengan dibantu narasi yang disampaikan oleh narator video guna memperjelas alur dan pemaknaan video tentang bangunan cagar budaya Kota Surakarta. Kemudahan penonton dalam memahami seluruh konten dalam video merupakan tujuan utama dan indikator keefektifan pembuatan video city branding. Secara aspek komuikatif, video timelapse memberikan peranan dalam menyampaikan sejumlah informasi dengan dibarengi perubahan gambar sebagai medium yang memperkuat visualisasi penonton. Terhadap estetika bangunan peninggalan Belanda, dapat ditampilkan pergerakan alam sekitar objek yang dibarengi dengan narasi mengenai sejumlah informasi terkait historis dan fungsi bangunan. Sedangkan bangunan Keraton Surakarta sebagai pusat kebudayaan Jawa di Surakarta dapat disampaikan narasi berupa data historis serta makna filosofis di setiap sudut arsitekturalnya. Hal tersebut perlu dilakukan dikarenakan untuk meningkatkan daya tarik wisatawan sebagai bentuk pelestarian cagar budaya di Kota Surakarta, sehingga hal yang menjadi faktor utama adalah tersampaikannya informasi terkait bangunan cagar budaya.

\section{KESIMPULAN}

Pada penelitian ini, membahas mengenai dua bangunan cagar yang merupakan bangunan sejarah besar yang pernah ada pada sejarah Kota Surakarta. Pada konsep arsitektural Belanda, tata letak arsitektural Belanda cenderung menghadap jalan raya penting dengan di belakangnya terdapat kanal ataupun tidak. Begitupula dengan konsep bangunan Benteng

Vastenburg yang berdiri kokoh menghadap ke sumbu jalan dan dikelilingi parit serta berdekatan dengan kanal (Kali Pepe). Simbol-simbol yang diunjukkan pada konsep bangunan arsitektural Benteng Vastenburg adalah kesan megah dan kokoh berdiri di perkomplekan bangunan Belanda di kawasan Jalan Gladag Surakarta. Sedangkan pada ekssotisme bangunan budaya Jawa adalah eksotisme Keraton Surakarta yang banyak mengandung sisi falsafah kehidupan. Video dengan menggunakan teknik timelapse dapat menawarkan nilai - nilai estetis yang mendorong viewers ke dalam suasana atau suatu objek. Pada bangunan Belanda, termasuk diantaranya benteng Vastenburg Surakarta yang merupakan bangunan outdoor akan mengedepankan visualisasi gambar terbaik di ruangan terbuka. Sedangkan apabila dalam mengambil gambar mengenai bangunan Jawa yang mengedepankan estetika interiornya, diperlukan kematangan perspektif terhadap bangunan interior atau perkiraan kualitas cahaya di dalam ruangan.

\section{DAFTAR RUJUKAN}

Andrés, M.A.N., \& Pozuelo, F. B., 2009. Evolution of the architectural and heritage representation. Landscape and Urban Planning, 91(2), pp.105112

Cahyandari, G. O. I, 2012. Tata Ruang dan Elemen Arsitektur Pada Rumah Jawa di Yogyakarta Sebagai Wujud Kategori Pola Aktivitas dalam Rumah Tangga. Jurnal Arsitektur KOMPOSISI, 10(2), pp. 103-118 
Rudy W. Herlambang, Diana Lukitasari, IGN Tri Marutama, Galih Pranata

EKSOTISME ARSITEKTUR BANGUNAN BELANDA DAN ARSITEKTUR BANGUNAN JAWA TERHADAP PENERAPAN TEKNIK TIMELAPSE VIDEO (TINJAUAN BANGUNAN CAGAR BUDAYA KOTA SURAKARTA)

Chawari, M., 2016. Benteng van den Bosch, Ngawi : Temuan Artefaktual Sebagai Cerminan Alat-Alat Kebutuhan Seharihari. Berkala Arkeologi. 36(2), pp.195-210

Chylinski, R., 2012. Time-lapse Photography: A Complete Introduction to Shooting, Processing and Rendering Timelapse Movies with a DSLR Camera. United States : Stay Curious Company

Fong, Yang Lai, Dyuty Firoz \& Wan Idros Wan Sulaiman, 2017, The Impact of Tourism Advertisement Promotional Videos on Young Adults, Journal of Social Sciences and Humanities, Vol. 12, No. 3, pp. 1-16

Hardiyanti, N. S., Antariksa, \& Hariyani, S., $2005 . \quad$ Studi Perkembangan Dan Pelestarian Kawasan Keraton Kasunanan Surakarta. Dimensi Teknik Arsitektur. 33(1), Desember 2005: pp.112 - 124

Herdian, D. I., Ramadhian, A. T dan Jani, K. 2015. Produksi Video Dokumenter Museum Radyapustaka di Surakarta dengan Mengaplikasikan Teknik Time lapse. Electrionic Publication Informatic Technique Faculty of Technique Alectrical and Informatic

Hernowo, B., 2015. Studi Tentang Lokasi Benteng-Benteng di Surakarta (1672, 1743, 1756, 1832). JURNAL ATRIUM. 1(1), pp. 39-47

Herrington, S., 2007. Gardens Can Mean, Landscape Journal. 26(2), pp.302-317.

Jannah, Bidriatul, Arifin, Zainul, Kusumawati, 2014, Pengaruh City Branding dan City Image Terhadap Keputusan Berkunjung Wisatawan Ke Banyuwangi, Jurnal
Administrasi Bisnis (JAB), Vol. 17 No. 1

Lestari, D. S. S., 2016. Interaksi Antara Upaya Konservasi Arsitektur dengan Pengembangan Pusat Kota Lama

Kolonial di Surakarta. Jurnal Teknik Sipil dan Arsitektur. 19(23), pp.1-8

Markus, T. A., Whyman, P., Morgan, J., Whitton, D., Maver, T., Canter, D.,

Flemimg, J. 1972. Building Performance. London: Applied Science Publishers Ltd

Murwadani, N.G., 2007. ArsitekturInterior Keraton Sumenep Sebagai Wujud Komunikasi dan Akulturasi Budaya Madura, Cina dan Belanda. Dimensi Interior, 5(2), pp.71-79

Nicholas, L.N., Thapa, B., \& Ko, Y.J., 2009. Residents' Perspectives of A World Heritage Site The Pitons Management Area, St. Lucia. Annals of Tourism Research. 36(3), pp. 390-412

Permana, A. A., Fianto, A.Y.A., \& Yosep, S.P., 2015, Penciptaan Destination Branding Keraton Kasunanan Solo Sebagai Upaya Meningkatkan Minat Kunjungan Wisatawan Domestik, Jurnal Desain Komunikasi Visual, Vol.4, No.1

Santosa, I., 2007. Kajian Estetika dan Unsur Pendukungnya pada Keraton Surakarta. ITB J. Vis. Art. 1(1), pp.108-12

Siregar, H.P.L., Kusmaningdyah, N.H., \& Yuliarso, H., 2017. Strategi Perancangan Kawasan Benteng Vastenburg Sebagai Museum Kota Surakarta Dengan Pendekatan Infill Design. Region. 12(1), pp.12-24

Sumalyo, Y., 1993. Arsitektur Kolonial Belanda di Indonesia. Yogyakarta: Gadjah Mada University Pers

Vecco, M. 2010. A definition of cultural heritage: From the 
tangible to the intangible.

$$
\text { Journal of }
$$

Cultural Heritage. 11(3), pp.321-324

Wardhani, D., \& Kusumawidagdo, A., 2019. Sense Of Place Pasar Barang Antik Triwindu:

Eksplorasi Faktor Fisik dan Sosial Pada Kompleks Arsitektur Komersial di Surakarta. MUDRA Jurnal Seni Budaya. 34(1), pp.136 - 145
Wirastari, V.A., \& Suprihardjo, R., 2012. Pelestarian Kawasan Cagar Budaya Berbasis Partisipasi Masyarakat (Studi Kasus: Kawasan Cagar Budaya Bubutan, Surabaya). JURNAL

TEKNIK ITS, 1(1), pp.C-63 - C67

Zain, Z., 2012. Pengaruh Aspek

Eksternal Pada Rumah Melayu Tradisional di Kota Sambas. Jurnal NALARs. 11(2), pp.1-11 